\title{
RADIOGRAFÍA DE LOS COMPORTAMIENTOS DEL PUEBLO EN LA COMARCA DEL RIBEIRO
}

\author{
Por \\ ENRIQUE BANDE RODRÍGUEZ
}

\section{RESUMEN}

El presente artículo, recoge a través de las Circulares y de las Visitas Pastorales hechas a diferentes parroquias de la comarca del Ribeiro la aplicación de una normativa de la iglesia oficial, desde mediados del siglo XVI, con el objetivo de moralizar y de domesticar los comportamientos religiosos y profanos del paisano gallego, mediante el control por parte de la iglesia de las fiestas, de las romerías y de los trabajos comunitarios, como eran las fiadas, las muiñadas, los velatorios, las comidas fúnebres y la participación en cofradías de pitanzas. Podemos afirmar que a pesar de las imposiciones clericales la cuaresma o la represión no triunfó nunca plenamente sobre las diversiones, sobre el carnaval.

\section{PALABRAS CLAVE}

Antropología gallega, Historia de la Iglesia. 


\begin{abstract}
This article deals with the rules applied by the official Catholic Church to different parishes of the Ribeiro area through Circulars and Pastoral Visits since the mid of the XVI Century. These rules tried to moralize and domesticate the secular and religious behaviour of the Galician peasants. The church controlled all kinds of local pagan festivals and religious pilgrimages community works, such as fiadas or spinning, muiñadas or milling, funeral wakes and lunches and gastronomic events. It could be said that in spite of clerical impositions. Lent or repression has never thouroughly triumphed over celebrations or carnival time.
\end{abstract}

\title{
KEYWORDS
}

Gallician Anthropologie, Church's History.

Igual que hicimos cuando tratamos el clero analizaremos los comportamientos del pueblo en el templo y fuera de él.

\section{1.- Asistencia a misa}

Manda que los días de fiesta asistan todas las personas a misa en su iglesia y a los que faltaren el abad o cura les multe en un real para alumbrar la lámpara del Santísimo Sacramento. El párroco obligue a sus feligreses a que traigan sus hijos a oír misa, se entiende los de siete años para arriba, para que fácilmente puedan venir todos a oír la misa en un día sus padres se repartirán a días interrumpidos de manera que la oigan unos en un día y otros en otro para que no se excusen de su obligación ${ }^{66}$.

${ }^{66}$ A.H.D.O.F.P. BEIRO, San Pedro. 22.4.9, fol. 51v. 


\section{2.- Comportamientos de los feligreses en la iglesia}

Manda que todos los feligreses estén en silencio cuando oyen misa y cuando asistan a algún misterio divino y en caso que no lo hagan el abad o cura por la primera y la segunda vez les condene en lo que justo fuere y llegando a la tercera les heche fuera de la iglesia y no les admita en ella hasta que cumplan la penitencia que por ellos les fuere impuesta y paguen la pena doblada ${ }^{67}$. Manda el visitador que asistan todas las personas a misa los días de fiesta en su iglesia y no hablen en la iglesia si no es preciso y necesario y esto sea con modestia y lo cumplan bajo la misma pena $^{68}$. Manda el visitador que todos los feligreses estén en silencio cuando estuvieren en la misa y con la devoción que en tales actos se requiere y no lo ejecutando así el abad o cura multe a cada uno por la primera vez en dos reales, por la segunda en cuatro y la tercera en seis aplicados para la cera y la lumbre de la fábrica del Santísimo ${ }^{69}$. Por cuanto le consta al visitador que los feligreses están con poca devoción mientras se dice la misa manda que el vicario multe a los que hablan por la primera y segunda vez en un real y a la tercera dará parte al Provisor ${ }^{70}$. Por cuanto en la iglesia como casa de oración debe observarse la mayor compostura, silencio y modestia manda que ninguna persona hable dentro de ella y en caso de contravención se tomen las providencias a que haya lugar, sobre lo cual celen tanto los párrocos con el mayor cuidado, siendo ellos y los demás sacerdotes los primeros en dar buen ejemplo y respetar el lugar sagrado $^{71}$. Manda que los feligreses de esta parroquia no hablen ni conversen dentro de la iglesia ni con otros bajo pena de incurrir en la indignación de Dios Nuestro Señor y de que en caso de contravención se tomarán las providencias que haya lugar lo cual celará el abad con el mayor cuida$\mathrm{do}^{72}$. Ninguno entre en la iglesia con pelo atado y así lo cumpla bajo pena de una libra de cera por cada uno que venga y el abad lo haga cumplir y

${ }^{67}$ A.H.D.O.F.P. BEIRO, San Pedro. 22.4.9, fol. 52.

${ }^{68}$ A.H.D.O.F.P. CARBALLEDA, San Miguel. 22.5.8, fol. 68.

${ }^{69}$ A.H.D.O.F.P. CARBALLEDA, San Miguel. 22.5.8, fol. 38.

${ }^{70}$ A.H.D.O.F.P. BEIRO, San Pedro. 22.4.9, fol. 48v.

${ }^{71}$ A.H.D.O.F.P. VIEITE, San Adrián. 22.18.9, fol. 103.

${ }^{72}$ A.H.D.O.F.P. VILLAR DE CONDES, Santa María. 22.18.7, fol. 59. 
ejecutar sobre lo que carga su conciencia y lo aplique a la fábrica ${ }^{73}$. Por cuanto el hablar e inquietar en la iglesia es suma irreverencia a S. Majestad Sacramentado que realmente allí se halla. Al presente encarga muchísimo S. Ilma. a todas las personas así hombres como mujeres esten con la mayor devoción que le fuere posible y manda al padre cura que si alguna persona hablare o causare alguna inquietud le multe en un real por cada vez la cual multa efectuará irremediablemente sobre lo que cargamos su conciencia $^{74}$. Manda que ninguna persona coma ni beba dentro de la iglesia según está mandado por Inocencio XI ni injurie a otro de palabra sino que debe estar con la reverencia que se debe tener en la casa de Dios y en presencia de S. Divina Majestad ${ }^{75}$. Manda el visitador que el abad no permita que en su iglesia se lean y publiquen cualesquier despachos y órdenes de justicias seculares ni que se pujen ni arrienden rentas ni se den voces ni levanten ruido dentro de ella por deber estar en la casa de Dios con toda quietud, humildad y reverencia y en caso que sus vecinos tengan alguna cosa que proponer en bien espiritual y utilidad de las almas y de la dicha iglesia nombren con todo sosiego cuatro personas timoratas y de inteligencia para acierto de lo que propusieren ${ }^{76}$.

\section{3.- Trabajo en días festivos}

S. Ilma. se halla informado de que algunos vecinos de esta feligresía no guardan como es su obligación los días festivos ejercitándose y trabajando en todas las labores según y de manera que lo hacen en los días de la semana sin ninguna excepción con carretos, y otras cosas mayores. Para que se evite todo escándalo y pernicioso abuso S. Ilma. manda que el abad y cura de dicha feligresía vele y tenga todo cuidado para que ningún feligrés trabaje en días festivos en sus labores y al que no lo hiciere por la primera vez le sacará de multa dos reales, por la segunda cuatro que aplicará S. Ilma. para aceite de la lámpara del Santísimo Sacramento y por la tercera vez no eje-

\footnotetext{
${ }^{73}$ A.H.D.O.F.P. CARBALLEDA, San Miguel. 22.5.8, fol. 67v.

${ }^{74}$ A.H.D.O.F.P. BEIRO, San Pedro. 22.4.9, fol. 75.

${ }^{75}$ A.H.D.O.F.P. VILLAR DE CONDES, Santa María. 22.19.7, fol. 13v.

${ }^{76}$ A.H.D.O.F.P. VILLAR DE CONDES, Santa María. 22.19.7, fol. 26v.
} 
cutado lo ordenado en este mandato dará cuenta a S. Ilma. para que castigue y apremie a los que fueren rebeldes y contumaces para cuyo fin así mismo manda S. Ilma. que el abad o cura de dicha feligresía nombre fiscales en ella que sean personas de conciencia y entereza y velen si sus feligreses trabajan en dichos días festivos y ejecutándolo le den cuenta para que les saque dichas multas y proceda contra ellos a lo más que se expresa en este mandato cargándole sobre ello la conciencia. Lo cual cumpla dicho abad y de no hacerlo se le hará cargo en la primera visita acerca de lo referido ${ }^{77}$. Cele el abad que sus feligreses no trabajen los domingos y más días festivos que no estén dispensados y que los santifiquen empleándose en oir misa, rezar el rosario y andar el viacrucis y ejercitándose en otras obras de virtud a que les animará y exortará con toda eficacia ${ }^{78}$. Manda a todos los feligreses de la dicha iglesia que guarden los domingos y fiestas no trabajando en ellas sino oyendo misa entera hasta acabar el evangelio postrero y haciendo les condene conforme a un real y no bastando dé cuenta al fiscal para que los rebeldes sean castigados con todo rigor ${ }^{79}$.

\section{4.- Educación de los hijos}

Por cuanto se halla informado de la grave omisión que tienen los padres en la educación de los hijos y familiares así en doctrina cristiana como en buenas costumbres de lo que se originan tantas ruinas espirituales como temporales y como la esperanza tiene enseñado, por tanto corrigiendo S. Ilma. al remedio en cuanto es de su parte exorta y manda a dichos padres y más que tengan hijos y familiares de menor edad aunque no hayan cumplido los 7 años procuren presentarlos al párroco en los días de fiesta a fin de que les instruya en la doctrina cristiana y en todo lo demás que tienen obligación de saber cuando lleguen a tener uso de razón, sobre lo que les carga S. Ilma. la conciencia y pone presente la terrible cuenta que les espera por su descuido y omisión en ello $^{80}$. Noté con

\footnotetext{
${ }^{77}$ A.H.D.O.F.P. VIEITE, San Adrián. 22.18.9, fol. 16.

${ }^{78}$ A.H.D.O.F.P. REGODEIGON, San Cristobo. 37.6.8, sin foliar.

${ }^{79}$ A.H.D.O.F.P. BEIRO, San Pedro. 22.4.9, fol. $6 \mathrm{v}$.

${ }^{80}$ A.H.D.O.F.P. REGODEIGON, San Cristobo. 37.6.8, fol. 13
} 
sentimiento que por la incuria de los padres de familia o por la distancia de que está la escuela o descuido de algunos maestros no hay mucha asistencia de los niños a la escuela a lo que es preciso poner remedio. Para ello los señores párrocos visitarán las escuelas y en todo están obligados por sí mismos o por su teniente o coadjutores si los hubiere a enseñar la doctrina cristiana a los niños especialmente los domingos y festivos y en la cuaresma y en el adviento a ser posible bien persuadidos como deben estar los señores párrocos de la necesidad de cumplir con una obligación tan principal $^{81}$.

\section{5.- Mujeres en la iglesia}

Manda que las mujeres no se mezclen en la iglesia con los hombres ni pasen de la puerta traviesa arriba ${ }^{82}$.

\section{6.- Mujeres solteras}

Por cuanto algunas mujeres solteras de este partido se separan de las casas y compañía de sus padres y tíos de lo que se han seguido y experimentado graves ofensas, pecados y escándalos para que esto se evite exorta S. Ilma. a todas las mujeres solteras de esta feligresía que no vivan solas ni separadas de sus padres, tíos y tutores y encarga S. Ilma. a dicho abad y cura que tenga todo cuidado de que se ejecute todo lo contenido en este mandato y contraveniéndolo alguna mujer soltera dicho abad dará cuenta a S. Ilma. para mandarles compeler y castigar a las que fueren rebeldes y contumaces $^{83}$. A falta de padres, parientes, tutores y curadores les manda que se pongan a servir donde pudieren ${ }^{84}$. Atendiendo a que algunas mujeres solteras viven solas y otras se emplean de la misma suerte vendiendo vino por menor en tabernas públicas expuestas de esta forma a muchos

${ }^{81}$ A.H.D.O.F.P. VIEITE, San Adrián. 22.18.9, fol. 149

${ }^{82}$ A.H.D.O.F.P. CARBALLEDA, San Miguel. 22.5.8, fol. 43.

${ }^{83}$ A.H.D.O.F.P. VIEITE, San Adrián. 22.18 .9 , fol. $17 \mathrm{v}$.

${ }^{84}$ A.H.D.O.F.P. REGODEIGON, San Cristobo. 37.6.8, fol. 3. 
peligros y desórdenes especialmente por hallarse las casas de los moradores de este país dispersas y algunas en montes despoblados como es costumbre, y deseando remediar en cuanto pueda los daños que de ello se siguen y que tengan cumplimiento las reales órdenes manda que los párrocos hagan amonestaciones sobre que las tales mujeres así solteras como viudas $\sin$ hijos que no sean de edad mayor vivan en compañía de sus padres o deudos próximos o con uno de los vecinos con quien mejor se les acomode y sea de cristianas costumbres y hallando que no surten efecto dichas amonestaciones pasarán sus oficios a las respectivas justicias para que pongan en ejecución dichas Reales Órdenes ${ }^{85}$.

\section{7.- Mujeres en tabernas}

Manda que los traficantes en vino no pongan en las tabernas para beneficiarlo al por menor a mujeres solteras y así lo cumplan bajo pena de incurrir ipso facto en la pena de excomunión mayor late sentencie y la multa de 4 ducados que para dicha fábrica exigirá el dicho abad y bajo la misma pena manda que ninguna mujer soltera viva sola a cuya ejecución procederá por censuras y absuelta de ellas habiéndolo cumplido ${ }^{86}$.

\section{8.- Entrada en tabernas}

Por cuanto ha llegado a nuestra noticia que algunas personas de dicha feligresía y de su contorno van y concurren a alguna taberna donde con notable escándalo están a jugar casi toda la noche de lo que se sigue haber muchas bullas, y chismeras en ellas unos con los otros como en sus casas con sus propias mujeres y con sus familias causando con este motivo muchos menoscabos y atrasos en su hacienda. Para evitar tan graves inconvenientes manda y encarga a S. Ilma. el abad y cura de dicha feligresía que procure con el mayor cuidado no haya dichos juegos en dichas tabernas

${ }^{85}$ A.H.D.O.F.P. VIEITE, San Adrián. 22.18.9, fol. 104v. REGODEIGON, San Cristovo. 37.6.8, sin foliar.

${ }^{86}$ A.H.D.O.F.P. VIEITE, San Adrián. 22.18.9, fol. 58v. REGODEIGON, San Cristobo. 37.6.8, fol. 3. 
para que de este modo poder evitar el que haya dichas bullas y quimeras así en las referidas tabernas como con sus propias mujeres y familia y apaciguar el escándalo que ocasionan entre los vecinos con los dichos juegos, pecados y ofensas que de ellos se originan contra Nuestro Señor ${ }^{87}$.

\section{9.- Escándalo y pecados públicos}

Manda que el cura procure con mucho cuidado el que se eviten pecados escandalosos en su feligresía y no queriendo enmendarse los delincuentes nos den aviso a nuestro provisor para que se remedie y no se dé mal ejemplo a los demás vecinos ${ }^{88}$.

\subsection{0.- Maldiciones}

Ordena y manda S. Ilma. que el dicho abad o teniente cura procure con el mayor cuidado desarraigar de sus feligreses la perniciosa costumbre de maldecir y hechar plagas poniéndoles presente la grave ofensa que hacen a Dios con ello, el mal ejemplo que dan a sus familias y a los mismos que los oyen ${ }^{89}$.

\subsection{1.- Pleitos entre los vecinos}

Por cuanto el visitador tiene noticias de que hay pleitos y encuentros entre el vecindario y los feligreses manda S. Ilma. al abad que se lleve bien con ellos, con suavidad y blandura particularmente en la iglesia y haciendo de su parte lo que se le mande en las visitas tocante a los dichos feligreses no obstante dé cuenta a S. Ilma. o a su fiscal para que se procede con todo rigor de derecho ${ }^{90}$.

\footnotetext{
${ }^{87}$ A.H.D.O.F.P. VIEITE, San Adrián. 22.18.9, fol. 20.

${ }^{88}$ A.H.D.O.F.P. BEIRO, San Pedro. 22.4.9, fol. 71v. CARBALLEDA, San Miguel. 22.5.8, fol. 66v. VILLAR DE CONDES, Santa María. 22.19.7

${ }^{89}$ A.H.D.O.F.P. VIEITE, San Adrián. 22.18.9, fol. 91v.

${ }^{90}$ A.H.D.O.F.P. BEIRO, San Pedro. 22.4.9, fol. 6.
} 


\subsection{2.- Bailes y danzas de seglares}

Manda S. Ilma. que dicho abad no permita en las fiestas que hay en las feligresías se baile y dance después del toque de la oración en adelante y que tampoco se hagan seranes juntándose de noche hombres y mujeres yendose a las casa o a los molinos y a los que esto contravenieren les multe dicho abad en 4 ducados aplicados a la fábrica de dicha iglesia ${ }^{91}$. Para cuya exación le da condición necesaria con facultad de proceder a ello por censuras absolviéndoles de ellas habiendo cumplido ${ }^{92}$.

\subsection{3.- Toque de la gaita-gaiteros}

Manda el abad que no permita que de aquí en adelante en las misas funciones y procesiones de su iglesia parroquial, capillas y santuarios de su districto se toque gaita alguna conforme S. Ilma. lo tiene prevenido en su carta circular expedida y en caso de que alguna persona se entrometa a tocar al tiempo de andar las procesiones estas se retiren a la iglesia, lo que cumpla dicho abad bajo pena de 50 ducados y con apercibimiento ${ }^{93}$. Manda S. Ilma. a los gaiteros que vienen a las festividades de las cofradías que hay en esta parroquia y más que se celebren en ella no toquen dadas que sean las oraciones por los muchos inconvenientes que de hacerlo se siguen lo que así en el día y en las vísperas de la festividad cumplan y si alguno ejecutare lo contrario siendo amonestado la primera y segunda vez el abad no le pague salario ni se admita en cuenta a los mayordomos además de dar cuenta a S. Ilma. para la mejor diligencia ${ }^{94}$.

${ }^{91}$ A.H.D.O.F.P. VIEITE, San Adrián. 22.18.9, fol. 58.

${ }^{92}$ A.H.D.O.F.P. REGODEIGON, San Cristobo. 37.6.8, fol. 3. VILLAR DE CONDES, Santa María. 22.19.7, fol. 32.

${ }^{93}$ A.H.D.O.F.P. REGODEIGON, San Cristobo. 37.6.8, fol. 12. VIEITE, San Adrián. 22.18.9, fol. 89v.

${ }^{94}$ A.H.D.O.F.P. VILLAR DE CONDES, Santa María. 22.19.7, fol. 32v. 


\subsection{4.- Romerías de seglares a santuarios}

Hallándose informado de los muchos excesos y daños espirituales y temporales que se originan especialmente entre gentes mozas en las romerías y santuarios a que suelen ir con frecuencia abusando del santo fin para el cual fueron erigidos aconseja y ordena a S. Ilma. que con su pastoral celo exorte a todos los subditos que procuren dirigirse a ellos con la moderación y la piedad que corresponde a buenos cristianos y se acomoden más bien a hacer cumplir y cumplan sus votos y ofertas en la iglesia parroquial en la que como casa más propia de oración serán más fructuosos y agradables a Dios ${ }^{95}$. Manda S. Ilma. que los vecinos de esta feligresía no permitan ni consientan que sus hijos y familias salgan de noche a las romerías de santuarios ni se queden a dormir dentro de ellos a las romerías de santuarios ni se queden a dormir dentro de ellos ni vuelvan ni anden de noche por las muchas ofensas que con estas ocasiones se cometen contra Nuestro Señor y siendo alguno omiso en lo referido el abad y cura le multe en dos reales la primera vez, por la segunda en cuatro y por la tercera dé cuenta a S. Ilma. para mandarle castigar rigurosamente cuyas multas aplicará S. Ilma. para el aceite de la lámpara del Santísimo ${ }^{96}$.

\subsection{5.- Fistas nocturnas}

Prohíbe con particular encargo los seranes y festines de noche entre hombres y mujeres por los muchos desórdenes e inconvenientes que la experiencia tiene acreditado acerca de lo que celarán los párrocos dichos encuentros cuanto sea posible exortando y amonestando a sus feligreses que no permitan por ningún pretexto semejantes festines y juntas nocturnas en sus casas y molinos con pretexto de hiladas ni por otro motivo alguno. A los padres, amos y señores les manda que cuiden como corresponde a su obligación de que sus hijos y criados no salgan de su casa a deshora de la noche por los graves inconvenientes y perjuicios que se siguen. Lo uno y lo otro teniendo presente la rigurosa cuenta que les espe-

${ }^{95}$ A.H.D.O.F.P. REGODEIGON, San Cristobo. 37.6.8, sin foliar.

${ }^{96}$ A.H.D.O.F.P. VIEITE, San Adrián. 22.18.9, fol. 18v. 
ra en caso de contravención y para que consiga por todos los medios el mayor servicio y honra de Dios, exorte igualmente a los justicias ordinarias cooperen de su parte como deben a que tenga cumplimiento lo aquí prevenido ${ }^{97}$. Por cuanto está mandado por nuestros predecesores no se hagan juntas nocturnas de noche así de hombres como de mujeres lo que llaman seranes y empallegadas por las muchas ofensas que se cometen contra Nuestro Señor. Para que se evite tan pernicioso vicio manda que los que consintieren de noche en sus casas o en sus molinos los tales festejos tocando y danzando el abad les multe a cada uno que consintiere lo referido en 10 ducados y a los padres de los hijos e hijas que se hallaren en tales molinos y seranes tocando y danzando les multará por la primera vez en cuatro reales, por la segunda en ocho y por la tercera dará cuenta a S. Ilma. para mandarles castigar rigurosamente, cuyas multas aplicará a la fábrica de esta feligresía ${ }^{98}$. Renueva expresamente los mandatos en que se prohíben con particular encargo los seranes y festines nocturnos entre hombres y mujeres por los desórdenes e inconvenientes que se experimentan lo cual celarán los párrocos exortando y amonestando a sus feligreses no permitan por ningún acontecimiento semejantes festines de noche en sus casas y molinos con pretexto de hiladas o de otro alguno y a los padres y amos sobre que cuiden como deben de que sus hijos y criados no salgan de noche de sus casas teniendo presente la obligación que le incumbe y la rigurosa cuenta que les espera en caso de omisión o contravención. Para que se consiga el mayor servicio de Dios exorta igualmente a los justicias ordinarias a que cooperen de su parte como corresponde a que tenga cumplimiento este mandato ${ }^{99}$. Manda que los vecinos de la feligresía no permitan a sus hijos y familia salgan de noche a romerías de santuarios ni que duerman en ellos ni que vuelvan a sus casas de noche por las muchas ofensas y pecados que en semejantes ocasiones se cometen contra Dios Nuestro Señor y en caso que quieran ir a dichos santuarios sea la ida y la vuelta por el día claro y no de noche como va referido. Le consta al abad que algunos vecinos no ejecutan lo que se les manda. Por la primera vez le sacará de multa dos reales y por la segunda cuatro ${ }^{100}$.

\footnotetext{
${ }^{97}$ A.H.D.O.F.P. VILLAR DE CONDES, Santa María. 22.19.7, fol. 59v.

${ }^{98}$ A.H.D.O.F.P. VILLAR DE CONDES, Santa María. 22.19.7, fol. 24v.

${ }^{99}$ A.H.D.O.F.P. REGODEIGON, San Cristobo. 37.19.7, fol. 25v.

${ }^{100}$ A.H.D.O.F.P. VILLAR DE CONDES, Santa María. 22.19.7, fol. $25 \mathrm{v}$.
} 


\subsection{6.- Permisión de unto como grasa del caldo}

Por cuanto el visitador está informado de las muchas necesidades que padecen los pobres quienes los viernes del año no tienen aceite para hacer los caldos para sustentarse por ello ordena y manda que puedan usar de manteca de puerco o unto según estilo de la tierra menos en cuaresma y en ello no haga escrúpulo alguno mediante la dispensa de S. Ilma. Así mismo los sábados del año no coman carne ni menudos solo lo que nuestra madre iglesia les permita y el abad repetidamente les explique de lo que lícitamente pueden usar ${ }^{101}$.

\subsection{7.- Casados}

Manda que los desposados solamente no cohabiten juntos ni asistan en partes sospechosas de lo que se siguen escándalos o peligro de pecar mortalmente y así mismo manda a los casados que no se velaron se velen dentro de los dos meses que manda el santo concilio y así los unos como los otros lo cumplan bajo pena de una libra de cera aplicada a la fábrica y el cura lo ejecute y de dichas penas se haga cargo el mayordomo de la fábrica poniéndolas por escrito para que de ellas le conste a S. Ilma. el visitador ${ }^{102}$.

\subsection{8.- Elecciones políticas}

Los señores eclesiásticos se abstengan de tomar parte activa o directa en elecciones de diputados a cortes o provinciales a no ser que por las circunstancias de las personas o por intereses de la iglesia convenga intervenir para cuyo efecto consultarán al prelado. En las elecciones municipales que interesan directamente al pueblo si por conocimiento de las personas resulta que es indiferente la elección de uno u otro candidato se abstendrán de intervenir al menos directamente, si por el contrario se esperasen fundamentalmente favores de uno $\mathrm{u}$ otro o protección de la iglesia y bien por la moralidad del pueblo y de otros se temiese que por su

\footnotetext{
${ }^{101}$ A.H.D.O.F.P. VILLAR DE CONDES, Santa María. 22.19.7, fol. 14.

${ }^{102}$ A.H.D.O.F.P. BEIRO, San Mauro. 22.4.9, fol. 73.
} 
conducta había de servir de escándalo en estos casos consultando con el prelado pueden emplear su legítima influencia en favor de uno o en contra de otro si bien absteniendose de tomar encargos de presidente o secretario electoral o de otros análogos ${ }^{103}$.

\subsection{9.- Elección de electores en las cofradías}

Deseando S. Ilma. también cortar las disputas, disensiones y desavenencias que pueden ocurrir con motivo y de la elección que se previene en las cofradías y hermandades ordena y manda que el abad en el año que corresponda hacer la elección avise al juez o mayordomo de la parroquia para que este lo haga o mande hacer al vecindario a fin de que en uno de los días de pascua o natividad se junten en el atrio de la iglesia o donde lo tengan de costumbre y procedan a nombrar doce electores de entre ellos a pluralidad de votos los que verificado su nombramiento conferenciarán y acordarán con dicho abad el de los expresados consiliarios ${ }^{104}$.

\subsection{0.- Los ermitaños}

Al ermitaño de Nuestra Señora del Rosario de Carballeda se le manda que no haga lumbre dentro de la ermita mayor de dicho oratorio por ser cosa indecente al culto divino, ni dentro de ella admita cosa indecente y que componga el techo del coro de dicha ermita ${ }^{105}$. Que componga la casa que está contigua a la dicha ermita y en ella viva y esto lo haga dentro de 6 meses bajo pena de excomunión mayor y de apercibimiento ${ }^{106}$.

\subsection{1.- Ingleses compradores de vino del ribeiro}

Por cuanto S. Ilma. está informado de que varios negociantes ingleses suelen concurrir a este Ribero a la compra de vino y que algunos sacerdo-

\footnotetext{
${ }^{103}$ A.H.D.O.F.P. VIEITE, San Adrián. 22.18.9, fol. 149v.

${ }^{104}$ A.H.D.O.F.P. VIEITE, San Adrián. 22.18.9, fol. 156v.

${ }^{105}$ A.H.D.O.F.P. CARBALLEDA, San Miguel. 22.5.8, fol. 43.

${ }^{106}$ A.H.D.O.F.P. CARBALLEDA, San Miguel. 22.5.8, fol. 38.
} 
tes del partido acostumbran a acompañarlos de bodega en bodega sirviéndoles de factores y apreciadores por sus propios intereses y fines particulares todo ello con indecencia de su estado hasta en el modo de acompañarlos llevándolos a la mano derecha y otras gestiones muy impropias manda S. Ilma. a todos los eclesiásticos de este Ribero y más de su obispado se abstengan de todo lo expresado en este capítulo y de otras inteligencias perjudiciales a su conciencia y al bien común. Todo ello en virtud de santa obediencia bajo pena de excomunión mayor y de aprecibimiento de suspensión y de proceder a lo más a que haya lugar lo que el abad de esta parroquia hará noticioso a sus feligreses ${ }^{107}$.

\subsection{2.- Trato de los ornamentos sagrados}

Se da el abuso de que en las festividades de Villar de Condes algunos mayordomos de las cofradías se llevan a sus casas la cruz y el pendón de la iglesia en las vísperas y en el día de la festividad y las vuelvan traer a dicha parroquia llegando a ella con notable indecencia casi a las 12 del día. Para evitar tan intolerable abuso manda que desde aquí en adelante el abad no permita ni consienta se lleve la cruz, imágenes y pendones a la casa de dichos mayordomos bajo pena de cuatro ducados ${ }^{108}$.

\subsection{3.- Rendición de cuentas al Abad}

Manda el visitador que todas las personas que de catorce años a esta parte estuvieren sin dar cuentas de los alcances de las cofradías el abad dentro de 15 días las den bajo pena de excomunión mayor ${ }^{109}$.

\subsection{4.- Instrucción religiosa}

Por hallarse informado de la omisión que tienen los padres y los amos en la educación de los hijos y familiares se originan tantas ruinas espiri-

\footnotetext{
${ }^{107}$ A.H.D.O.F.P. VIEITE, San Adrián. 22.18.9, fol. 67v.

${ }^{108}$ A.H.D.O.F.P. VILLAR DE CONDES, Santa María. 22.19.7, fol. 24v.

${ }^{109}$ A.H.D.O.F.P. CARBALLEDA, San Miguel. 22.5.8, fol. 38.
} 
tuales y temporales como la providencia tiene enseñado por ello para poner remedio en cuanto esté de su parte exorta y manda a dichos padres y amos que tengan hijos y familiares de menor edad aunque no hayan cumplido 7 años procuren personarlos al párroco en todos los días de fiesta a fin de que este les instruya en doctrina cristiana y en todo lo demás que tienen obligación de saber cuando lleguen a tener uso de razón. Ante esto les carga la conciencia y pone presente la terrible cuenta que les espera por su descuido y omisión en ello ${ }^{110}$.

\subsection{5.- La salutación angélica}

Deseando promover la piadosa y tierna devoción de la salutación angélica que con mucho consuelo ha visto se observa y practica en esta parroquia concede 40 días de indulgencias por cada vez que lo ejecutaren. La persona que por devoción quisiera encargarse de tocar en los tres tiempos acostumbrados, a saber, por la mañana, al mediodía y al anochecer como también a las benditas ánimas que será algún tiempo después del último toque del avemaría y otros 40 a cada una de las personas que las rezaren y lo mismo a los que también rezaren un padre nuestro y un avemaría por las ánimas cuando se toque a ellas ${ }^{111}$. Manda que en esta parroquia se observe la práctica y la piadosa costumbre de la salutación angélica tocando al efecto la campana por la mañana, al mediodía y al anochecer del modo que se hace en otras parroquias de la diócesis ordena y manda que así se ejecute todos los días de hoy en adelante dando para ello la señal con la campana en los tres tiempos señalados y deseando también que los fieles difuntos no carezcan de todos aquellos sufragios que los vivos pueden y deben aplicarles aún desde sus mismas casas $u$ otro cualquier parte donde se hallaren ordena y manda que después de haber tocado a las oraciones al anochecer se toque también a las benditas ánimas y después de una breve pausa dando nueve campanadas en tres tiempos y de tres en tres en cada uno para que las encomienden a Dios ${ }^{112}$.

\footnotetext{
${ }^{110}$ A.H.D.O.F.P. VIEITE, San Adrián. 22.18.9, fol. 90v.

${ }^{111}$ A.H.D.O.F.P. VIEITE, San Adrián. 22.18.9, fol. 154.

${ }^{112}$ A.H.D.O.F.P. REGODEIGON, San Cristobo. 37.6.8, sin foliar.
} 
Manda que el luminario prosiga en las oraciones del avemaría a boca de la noche y después del toque de las ánimas $\mathrm{S}$. Ilma. concede 40 días de indulgencias a todos los fieles que recen de rodillas la oración angélica y así mismo concede otros 40 días de indulgencias a los que con devoción rezaren el Pater-Noster, avemaría o por las ánimas de sus difuntos ${ }^{113}$.

\subsection{6.- El viático}

Manda S. Ilma. que el dicho abad exorte a sus feligreses a acompañar a S.D. Majestad cuando se lleve por modo de viático a los enfermos y para que más bien se animen a ello por cada vez que lo ejecuten les concede S. Ilma. 40 días de indulgencias ${ }^{114}$. Ha sido informado el visitador que ha habido y hay descuido en algunas personas en acompañar el Santísimo Sacramento que es el verdadero cuerpo del Señor y Redentor Jesucristo. Encargamos a los dichos feligreses de la feligresía tangan particular cuidado y devoción y en oyendo la campana que diere la señal de que sale el Stmo. Smto. de la iglesia para salir acompañandolo hasta que vuelva a ella demás de la obra meritoria que es que se hace agradable a Dios visitando los enfermos ganan 100 días de perdón los que le acompañen ${ }^{115}$. Manda que toda persona que viere llevar fuera de la iglesia el Santísimo Sacramento hinque las rodillas para hacer la reverencia y luego lo acompañe hasta que vuelva a la iglesia y no lo haciendo no teniendo impedimento legítimo que le pueda excusar le multe el vicario por la primera vez en medio real, por la segunda en dos y por la tercera de parte a $S$. Señoría o a su provisor para que se prevea el remedio ${ }^{116}$.

\subsection{7.- Funerales y honras fúnebres}

Tiene S. Ilma. noticia de que en los reinos de Andalucía y Castilla han muerto muchas personas de esta feligresía así casadas como solteras, como

\footnotetext{
${ }^{113}$ A.H.D.O.F.P. VILLAR DE CONDES, Santa María. 22.19.7, fol. 15.

${ }^{114}$ A.H.D.O.F.P. VIEITE, San Adrián. 22.18.9, fol. 59.

${ }^{115}$ A.H.D.O.F.P. BEIRO, San Pedro. 22.4.9, fol. 43.

${ }^{116}$ A.H.D.O.F.P. BEIRO, San Pedro. 22.4.9, fol. 43v.
} 
también hijos de familias que han muerto aquí y no les quieren tener los funerales según su calidad y como es costumbre y obligación precisa de los padres y de los herederos. Por tanto S. Ilma. manda que todos los referidos cumplan los funerales de sus hijos padres o hermanos que hayan muerto fuera del reino ${ }^{117}$.

\subsection{8.- Oración por los difuntos}

Por cuanto es cosa saludable hacer oración por las almas de los difuntos, por las constituciones sinodales y sínodos de este obispado está mandado a todos los abades y curas que hagan tañer a las ánimas todas las noches, manda al dicho vicario tenga cuidado de que después de las oraciones se haga señal por las ánimas del purgatorio para que todos las encomienden a Dios y rueguen que las libre de las penas que padecen y concedió a todas las personas que rezaren un padrenuestro y un avemaría por las ánimas de sus padres, madres, hermano, pariente u otra persona de su obligación o por las que más necesidad tuvieren de sus oraciones en dichas penas 40 días de indulgencias y de perdón ${ }^{118}$.

\subsection{9.- Precepto Pascual}

Son pocos los feligreses que han dejado de cumplir con el precepto pascual y por las exortaciones que dirijí después de la visita del templo podrán los señores párrocos conocer mis deseos para que continuen amonestándoles que los reciban en cualquier tiempo que vengan con las debidas disposiciones y que entre tanto no les admitan por padrinos en los bautismos y si llegado el año que viene continuasen en su pertinacia ni les bendigan sus casas a excepción de que fuesen casados y el otro cónyuge hubiese cumplido, ni lo admita a la sepultura eclesiástica, además les excluirán de cualquier cofradía o hermandad a la que perteneciesen ${ }^{119}$.

\footnotetext{
${ }^{117}$ A.H.D.O.F.P. CARBALLEDA DE AVIA, San Miguel. 22.5.8, fol. 74.

${ }^{118}$ A.H.D.O.F.P. BEIRO, San Pedro. 22.4.9, fol. 42.

${ }^{119}$ A.H.D.O.F.P. VIEITE, San Adrián. 22.19.21, fol. 150.
} 


\section{3.- CONCLUSIÓN}

A través de los sínodos de las Circulares y de las visitas pastorales la «Iglesia Oficial» hace una campaña dirigida a la «sacralización» de la figura del sacerdote y de la sociedad laica, pone de relieve el papel de la iglesia en la domesticación de las costumbres del clero y en la moralización de las del pueblo. Los objetivos perseguidos por la «Iglesia Oficial» como puede verse siguiendo las visitas pastorales son:

La moralización o domesticación del clero haciendo que sus miembros cuiden su figura y su porte exterior como es el vestido, el cabello y su conducta como es la asistencia a fiestas, bailes, y ferias, a bodegas, mercados, fiestas y lugares de reunión de seglares. También dieron normas prohibiendo el trato del clero con mujeres, y a desterrar de sus casas las mancebas y las barraganas. De esta forma las autoridades eclesiásticas emprendieron una campaña dirigida a sacralizar la figura del sacerdote y sus funciones y a la moralización de sus costumbres.

La moralización y domesticación del pueblo mediante el control por parte de la iglesia de las fiestas, de las romerías, de los trabajos comunitarios como eran las fiadas, las muiñadas, los velatorios, las comidas fúnebres y la participación en cofradías de pitanzas. Todo esto cae dentro de una campaña que tiene como objetivo la clericalización de las costumbres, la sacralización de la figura del sacerdote y la búsqueda de la diferenciación entre lo sagrado y lo profano.

El papel protagonista de la represión del clero y del pueblo gallego lo tuvo y lo sigue teniendo en sus manos la «iglesia oficial». Al verse impotente la «iglesia oficial» apeló siempre a la colaboración de los padres y de los cabezas de familia quienes deben cuidar la educación religiosa y moral de sus hijos. Muchas veces la «iglesia oficial» hizo esto a través de una acción represiva con la ayuda del brazo secular aunque el papel de las autoridades laicas en este terreno nos consta que fue menor que el de los miembros de la «iglesia oficial» quienes han ejercicio una acción absorvente sobre la sociabilidad y la moralidad del pueblo gallego como lo demuestran las actas dictadas por las Reales Ordenanzas a cerca de las hiladas, muiñadas, las fiestas de carnavales, las celebraciones de ferias en domingos, las visitas a molinos y los pecados públicos como el amancebamiento y los juegos. La represión en el ámbito cultural la ejerció siempre la «iglesia oficial» secundada por las autoridades civiles quienes nun- 
ca extremaron su acción sobre el control de las formas de sociabilidad campesina y cuando lo hacen es a instancias de las autoridades eclesiásticas. Debemos recordar en este terreno los actos dictados por Reales Acuerdos contra las hiladas, las muiñadas, las celebraciones festivas en domingos, los carnavales, las reuniones en molinos y los dictados para controlar los pecados públicos como son el amancebamiento, la usura, los juegos de adivinación y las blasfemias. En el mundo rural gallego y aun en villas y ciudades el proceso de clericalización y domesticación de las costumbres del campesinado tuvo siempre como objetivo la sacralización y santificación del espacio profano y la erradicación de múltiples formas de sociabilidad popular. La «iglesia oficial» como dejamos dicho muchas veces tuvo que pedir ayuda a las autoridades laicas sobre todo para castigar los pecados públicos como eran el amancebamiento, las hiladas, las pandeiradas, las muiñadas y las fiestas. La «iglesia oficial» en los mandatos de las visitas pastorales delimita el sentido religioso de las festividades, frente a las múltiples «supersticiones», delimita también el espacio sagrado y el profano y lucha contra ciertas prácticas religiosas mal llamadas supersticiones.

Todas estas medidas van encaminadas a acreditar su autoridad, su prestigio y su ejemplaridad. Con todas estas medidas y otras semejantes se consuma la sacralización de la figura del sacerdote iniciada en el Concilio de Trento. La campaña de clericalización tiene como objetivo lograr un estamento eclesiástico de vida edificante en su porte externo e interno dotándolo de una mejor formación intelectual y de una ejemplaridad de costumbres. Dicha campaña cae dentro de las medidas preventivas que figuran en los sínodos, las circulares y las visitas pastorales, donde se le propone al clero un ideal de vida basado en el recogimiento, en el celo pastoral y en una forma de vida que distinga a los clérigos de los miembros del resto de la sociedad por la vivencia de la castidad, por el ejercicio de ciertas virtudes y el cuidado de su porte extremo y de signos de comportamiento como son: el vestido, el corte del pelo y la no asistencia a actos festivos o profanos como bailes y la entrada en tabernas. La disociación que se pretende es a la vez espiritual y social, con el fin de «sacralizar» debidamente una sociedad que a menudo confunde lo sagrado y lo profano y la actuación del clero. Mediante las constituciones sinodales, las circulares y las visitas pastorales la autoridad diocesana emprende una campaña de «sacralización» de la figura y de la función del sacerdote y de la moralización de sus costumbres. La clericalización se entiende 
como una condición previa a la cristianización del campesinado. La familiaridad con lo sagrado y la confusión entre lo sagrado y lo profano exige una acción de la que resulte una nueva pedagogía en el tiempo y en el espacio conforme al modelo cristiano. La sacralización de la figura y de la función del sacerdote tiene una contrapartida en un proceso de diferenciación y de separación tajante entre lo sagrado y lo profana ante su confusión en la religiosidad popular y ante la excesiva familiaridad con lo sagrado que presentan al menos algunas formas de vida campesina.

Desde los inicios de la época moderna en las visitas pastorales se insiste en la diferenciación de los espacios sagrado y profano en los cuales discurre la vida del hombre con normas y reglas bien diferenciadas. El lugar sagrado está caracterizado por su decoro externo y por ello los tamplos deben estar cerrados con la llave, compuestos y limpios para que allí no encierren animales inmundos y sucios así como cabras, ovejas, vacas y puercos ensuciando el suelo. También mandan los visitadores erradicar de estos lugares ciertas actividades profanas que tienen como marco el recinto eclesial, la iglesia y el atrio. Entre las prohibiciones más importantes están las referentes a la celebración de comidas y banquetes en los días de todos los santos y de difuntos con ocasión de mortuorios y de honras fúnebres, la celebración de ferias y mercados dentro de la iglesia y de reuniones para tener negocios seculares o para meter en los lugares sagrados gentes, armas y bestias.

La conciencia de hallarse en lugar sagrado debe esteriorizarse en la compostura y en el recogimiento. Por ello las visitas recomiendan a los feligreses que no hablen en las iglesias. En las visitas aparecen como objetivos claros por una parte sacralizar los espacios profanos, controlarlos y santificarlos como son las tabernas, los molinos, erradicar o depurar determinadas formas de sociabilidad popular como romerías, ferias, hiladas, muiñadas y comidas de cofradías.

La conclusión que podemos sacar de los datos extraídos de las visitas es que a pesar de la imposición clerical la cuaresma o cuarentena tridentina léase represión no triunfó nunca plenamente sobre el carnaval y las diversiones dado que el divertirse en las fiestas y el servir y alabar a Dios no son modos incompatibles sino simplemente dos caras de la vida profundamente religiosa del campesino gallego quien también es vitalmente sociable y profano sin disociar nunca los dos aspectos el religioso y el lúdicorecreativo por ser uno y el mismo, el hombre, el sujeto de ambos. 